\title{
Confín geográfico, refugio indígena, pueblo de indios y etnogénesis en el Huasco Alto, (Chile) ${ }^{1}$
}

\author{
Raúl Molina Otárola² y Luis Campos Muñoz ${ }^{3}$
}

\begin{abstract}
RESUMEN
El presente trabajo plantea la directa relación que existe entre etnogénesis y territorio geográfico, entre los habitantes originarios en el Norte Chico de Chile. La etnogénesis corresponde a la aparición sorpresiva de una identidad considerada hasta entonces como desaparecida, siendo en la actualidad una variante de los procesos relacionados a las identidades étnicas. Se plantea discutir la correspondencia entre los antiguos pueblos de indios coloniales y el proceso de surgimiento de la identidad diaguita contemporánea, considerando que es el último pueblo indígena que ha sido reconocido por el Estado de Chile. Para esto se analiza la cuna de la identidad diaguita contemporánea: el Huasco Alto. Se plantea que las condiciones que favorecieron este proceso etnogenético entre los huascoaltinos, fue que su territorio se constituyó a la mirada del hispano en un confín geográfico y en un refugio indígena durante el periodo colonial, y que marcó una frontera con el español, espacio en que su población originaria logró mantener el control de las tierras y en ellas su reproducción social y económica hasta el presente.
\end{abstract}

Palabras claves: Confín geográfico, Pueblo de Indios, Etnogénesis diaguita, Huasco Alto.

\begin{abstract}
The present work raises the direct relation that exists between ethnogenesis and geographic territory, conserved by the original habitants in the north of Chile. Ethnogenesis corresponds to the surprise appearance of an identity considered until then as disappeared, being at present a variant of the processes related to the ethnic identities. It goes on to discuss the correspondence between the ancient indigenous people of the colony and the process of the emergence of contemporary diaguita identity, considering that they are the last indigenous people that have been recognized by the State of Chile. For this we analyze the cradle of contemporary diaguita identity: Huasco Alto. Itis argued that the conditions that favored this ethnogenetic process among the Huascoaltinos was that their territory, which was constituted in view of the Hispanic as a geographic border and an indigenous refuge during the colonial period, marked a border with Spanish, space in whichits original habitants managed to maintain control of the land and in them, their social and economic reproduction until the present.
\end{abstract}

Key words: Geographical border, indigenous people, diaguita Ethnogenesis, Huasco Alto.

Este artículo es producto del Proyecto Fondecyt N. 1150876, "La etnogénesis y el reconocimiento. Estudio comparado de cuatro procesos etnogenéticos en Chile y su impacto en la sociedad civil y el mundo académico", pesquisa patrocinada por la Escuela de Antropología de la Universidad Academia de Humanismo Cristiano y realizada en colaboración con el Centro Interdisciplinario de Estudios Interculturales e Indígenas- CIIR, Código de Proyecto: CONICYT/FONDAP/15611006. Artículo recibido el 30 de diciembre de 2016, aceptado el 30 de junio de 2017 y corregido el 30 de julio de 2017.

Centro de Estudios Interculturales e Indígenas CIIR (Chile).E-mail: raul17molina@gmail.com

Universidad Academia de Humanismo Cristiano (Chile). E-mail: luiseugeniocampos@gmail.com 
Entre territorio geográfico y procesos de surgimiento de identidades étnicas o etnogénesis existe una relación fundamental, que está en el sustrato de los procesos de construcción y surgimiento de nuevos pueblos indígenas. El surgimiento de estas nuevas identidades socioculturales indígenas ha tenido como fundamento el espacio ocupado, la memoria y las prácticas culturales y económicas que se efectúan sobre territorios y lugares, que se fronterizaron étnicamente (como ocurrió en el Huasco Alto). En este proceso el espacio geográfico juega un rol relevante en la medida que se le carga material y simbólicamente de contenidos indígenas, se valoriza y existe una producción de sentidos y significación del territorio (Soja, 1989; Zusman, 2013), donde el espacio no es solo materialidad (Lindón y Hiernaux, 2012), sino también ancestralidad y memoria que se ancla a los lugares, los paisajes y el territorio habitado (Nora, 2009).

Es así como en el Norte Chico de Chile ha resurgido el pueblo diaguita, el que ha tenido como fundamento histórico territorial provenir de los antiguos Pueblos de Indios, establecidos entre los siglos XVII y XVIII (Molina et al., 2005; Escolar, 2000). Estos pueblos se constituyeron por las disposiciones de las autoridades coloniales en espacios geográficos bien delimitados. Fueron radicaciones de indígenas que consideraron el reconocimiento y asignación de tierras que quedaron protegidas por decreto real, tierras que, en algunos casos, durante los siglos republicanos, lograron ser conservadas en distintas proporciones, salvándose de los variados intentos de liquidación legal o de las compraventas que operaron en los siglos XIX y XX.

La conservación de las tierras de raigambre indígena, la persistencia en el poblamiento basado en el parentesco ancestral, el sentido de lugar que le otorgan sus descendientes (Nora 2009) y la memoria territorial y cultural, están en la base de la reciente formación de comunidades diaguitas en el Norte Chico. Es el caso de la comunidad diaguita de Chalinga, en la provincia de Choapa en la Región de Coquimbo (Com. Indíg. Taucán 2014), y especialmente, de las numerosas comunidades diaguitas formadas en el Huasco Alto, de la Región de Atacama. En este último lugar se inaugura la etnogénesis diaguita, una identidad indígena que se había sumergido y negado en el periodo republicano y que desde las ciencias sociales creían extinguida. Se consideraba a los diaguitas solo como expresión prehispánica, estudiada en sus evidencias arqueológicas (Cornely, 1956; Iribarren, 1956). El proceso de etnogénesis vino a negar la invisibilización histórica-territorial de los diaguitas, ya que estos habitantes de antiguos pueblos de indios apoyándose en sus apellidos y linajes, en la tierras conservadas y en la continuidad económica productiva, avanzaron primero hacia una auto identificación como diaguitas y posteriormente, en el año 2006, lograron el reconocimiento como Pueblo Indígena, siendo incorporados a través de la Ley N. 20117 a la Ley Indígena 19.253 (Molina et al., 2005; Campos, 2016).

Cuando hablamos de etnogénesis nos referimos a un concepto que se ha aplicado a diferentes situaciones de construcción, reemergencia y reetnificación de diversos tipos de colectivos culturales. Los primeros trabajos relativos a etnogénesis se desarrollan a principios del siglo XX y apuntan a caracterizar el surgimiento de nuevas identidades afrodescendientes y también de diversas naciones en Europa (Luna, 2014). Con posterioridad se han utilizado este y otros conceptos relacionados como emergencia, reetnificación, transfiguración étnica y resurrección cultural para dar cuenta de poblaciones que comienzan a construir una identidad diferente de la nacional, edificando un imaginario histórico, recomponiendo una memoria local y auto reconociéndose bajo un etnónimo ya existente y que los vincula a algún pueblo indígena. En este caso en particular, se trata entonces de una nueva identidad, la diaguita, que se suponía extinguida en el Norte Chico de Chile. Para Bartolome (2003) el concepto de etnogénesis ha sido tradicionalmente utilizado 
para dar cuenta del proceso histórico de la configuración de colectividades étnicas, como resultado de migraciones, invasiones, conquistas o fusiones y también ha sido esgrimido para designar el surgimiento de nuevas comunidades que se designan a sí mismas en términos étnicos, para diferenciarse de otras sociedades o culturas que perciben como distintas a su autodefinición social (Bartolomé, 2003).

En el caso de la etnogénesis diaguita, esta se expresa primero en el proceso de búsqueda y construcción de una identidad local, y en seguida, ocurre el reconocimiento legal por el Estado y la sociedad. Por su parte, Appadurai (2001) destaca que en los procesos identitarios, como también en la aparición de nuevas identidades étnicas, se debe considerar a los agentes de estos procesos y no solamente verlos bajo el alero de impactos de fuentes externas, destacando la acción de las personas. Esto es lo que sucede en el Huasco Alto, donde la población en base a la reconstrucción de una antigua historia indígena se auto reconoce diaguita. Esta nueva identidad pasa a constituirse como pueblo para hacer un uso político y cultural diferenciado del resto de la sociedad nacional (Isla, 2002). Sin embargo, además de la nueva representación social-cultural y política de lo étnico que destaca el enfoque antropológico, es preciso darle sustento en la geografía que dialoga con el habitar y con el sentido de lugar, pues la etnogénesis está necesariamente vinculada al territorio ocupado y recordado, como ocurre en el Huasco Alto.

Es por ello, que planteamos que en el surgimiento de la etnia diaguita existe una estrecha relación entre espacio geográfico y etnogénesis, donde la geografía del lugar y su conformación socio espacial, otorgan identidad cultural que se expresa en nuevas formas de valorar el espacio habitado, cargado de atributos que son convertidos en etno-territorios que dan fundamento a la discursividad étnica, histórica y territorial.

En el Huasco Alto, las condiciones que posibilitan la sobrevivencia de la población originaria estuvieron dadas por factores geográficos, económicos y socio culturales. Este fue un espacio que se constituyó durante largo tiempo en un "confín geográfico", un lugar de "refugio indígena" especialmente por su localización en la cordillera, con una accesibilidad reducida, condiciones que permitieron la supervivencia y cierta autonomía productiva, lo que favoreció la permanencia del poblamiento originario (Aguirre Beltrán, 1967; Molina, 1997)4. La población indígena allí concentrada conservó el territorio mediante diversas formas de resistencia cultural y productiva, que posibilitaron la ocupación prolongada hasta la actualidad. Y al igual que en el caso de los huarpes en Argentina (Escolar, 2007), dependiendo del momento histórico, su reconocimiento étnico y social fue variando. Durante los siglos XVI, XVII y XVIII, la administración colonial hispana los nombró genéricamente indios del Huasco Alto. Durante los siglos XIX y XX del periodo republicano lo indígena desapareció del discurso y categorías del Estado y los antiguos indígenas huascoaltinos fueron reconocidos socialmente como agricultores y crianceros. A principios del siglo XXI, tras el proceso de emergencia étnica, estos pasaron a auto reconocerse diaguitas, en virtud de sus antecedentes históricos y culturales. En la actualidad, producto del impacto que causó en el año 2006 el reconocimiento de este nuevo pueblo indígena en Chile, han proliferado las comunidades diaguitas y las asociaciones indígenas a lo largo del país. Sólo en la zona de Vallenar existen más

\footnotetext{
Al respecto Gonzalo Aguirre Beltrán (1967) señala que las Regiones de Refugio son espacios donde han persistido características geográficas, demográficas, ideológicas, políticas y sociales de orden arcaico y primitivo, que ya no existen en otras zonas del país debido al progreso y en donde desde la época colonial conviven dos agregados humanos, uno de los cuales se caracteriza por ser el que ejercita el dominio sobre la indígena que vive en la zona circundante.
} 
de cuarenta organizaciones, a las que se le suman las de Coquimbo, valle del Elqui, Ovalle, Vicuña, Salamanca, Petorca y Valparaíso.

\section{Confín geográfico y refugio indígena}

La etnogénesis puede producirse a partir de un conjunto de variables que han sido trabajadas a partir de diversos procesos emergentes de los últimos veinte años. Se ha puesto énfasis tanto en la invisibilización histórica producto de políticas de alteridad nacionales o regionales, en los factores externos que pueden llegar a gatillar el desarrollo del proceso identitario, como también en el impacto que han tenido las políticas públicas y el asistencialismo lo que ha incidido en el identificarse como indígenas por un sentido instrumental. Estos movimientos han surgido la mayor parte de personas y en espacios en donde no se reconocía la pertenencia indígena, no obstante, existieran en algunos casos evidentes muestras de vínculos con antiguos pueblos precolombinos. Esta vinculación se da con elementos de cultura material, con actividades productivas, cotinuidad de parentesco, cosmovisionales y territoriales, esta última variable determinante en el caso diaguita.

Planteamos así que la etnogénesis diaguita ha tenido como sustrato la presencia de esta población indígena en un territorio que históricamente les ha pertenecido por permanencia y ancestralidad. En el caso del Huasco Alto sus habitantes han persistido en su ocupación territorial hasta la actualidad, mostrando una continuidad del poblamiento en el tiempo. Esta ocupación incesante pudo tener como aliado el emplazamiento geográfico, puesto que el extenso valle que ocupan en la Cordillera de los Andes, se constituyó en un confin geográfico, un más allá de lo que alcanza la vista o de lo que se puede ver, debido a que se encontraba alejado de las vías de comunicación que longitudinalmente atravesaban la depresión intermedia y los caminos de la costa.

Al Huasco Alto durante el periodo colonial se accedía por estrechas huellas y senderos de arriería. Al valle que habitaban se le conocía con el nombre de "Río de los Indios" o de los "Naturales" (Amat y Junient, 2004; Morales, 1981; Pérez Rosales, 1986), que actualmente es nombrado como río Tránsito. Este río se forma de los afluentes cordilleranos, los ríos Chollay, Conay, Cazadero y Valeriano, que provienen de las zonas de las más altas cumbres y cajones enclavados en la Cordillera de los Andes. Aguas abajo el antiguo río de los indios, en el lugar llamado Ramadillas, se junta con el río del Carmen, antiguamente denominado "Río de Ramos"5 o de los "Españoles". Allí forman el río Huasco. En el siglo XVIII un documento de la geografía e hidrografía del Reyno de Chile, decía que la "Junta del Río de los Indios con el Río de Ramos componen el Río Huasco" (Amat y Junient, 2004: 306-307).

Este territorio, el Huasco Alto, era un confín geográfico indígena. Lo españoles se asentaron en el valle del actual río Carmen, entre Alto del Carmen y San Félix, y los indígenas quedaron relegados en la cuenca del río Tránsito, generándose espacios geográficos diferenciados étnicamente, que dieron nombre a los valles y los ríos que lo riegan; "...en el río del Carmen (o de Ramos), donde

El nombre de río de Ramos provino del encomendero de indígenas que ocupó las tierras del actual Valle de San Félix hasta el Alto del Carmen; “...desde 1607 los gobernadores de Chile principiaron a hacer cesión de tierras en el Huasco y en algunas estancias de los alrededores, de tal manera que en el año $1700 . .$. , era dueño casi todo el valle del Huasco y sus demasías el español don Jerónimo Ramos de Torres que residía en el río de Españoles o del Carmen..." Morales (1896: 186). 
residían muchos españoles a quienes se había concedido lotes de terreno; y en el río del Tránsito, donde existían algunas tolderías de indios. De aquí la distinción entre río de los españoles y de los naturales que se ha hecho de los dos" (Morales, 1896: 52). En el siglo XIX, se mantenía el nombre de estos valles. Vicente Pérez Rosales en 1857 señala que: “El río Huasco, ...está formado por el concurso de cinco torrentes andinos y del río de los Naturales (Tránsito) aumentado por el río de los Españoles (del Carmen)" (Pérez Rosales, 1986 [1859]: 89). Esta diferenciación étnica-territorial está vigente hasta la actualidad, como relata uno de sus pobladores: "Aquí hay una situación muy especial, estos dos valles, de San Félix (en el río del Carmen) y del Tránsito, por allá están los españoles, y por acá estamos los indios, claro, los descendientes de indios..." (José López, Chanchoquín, 11 de febrero de 2005 en: Molina et al. 2005)

Ya en el periodo colonial el río de los indios adquirió el carácter de refugio de la población indígena, debido a las características del espacio habitado. La geografía de valles estrechos, quebradas y cerros, así como sus pasos al oriente de la cordillera, favoreció que fuera un espacio que daba amparo a los indígenas que evadían los cobros de los encomenderos y a la vez, se convirtió en un refugio de los fugados de otros valles, como revela en 1757 la Carta de Amat y Junient.

"La distancia en que viven ... da motivos para mayores desordenes con el seguro de que es fácil ocultar no habiendo vecinos, que los adviertan a que concurre lo estrecho del valle que en algunas partes solo deja la caja precisa para el rio, y así es mucho más fácil esconderse a cualquiera persona estraña, que entre como suelen hacerlo los indios solteros, cuando el encomendero saca algunos para que le paguen tributo con su servicio personal; de suerte que siendo más fáciles de hallarlos casados porque su mesma familia los sujeta son estos los que regularmente se salen i por su falta quedan los otros a su libertad viviendo con sobrado desorden; cuando esto llega a saberse aun entre los demás indios ha pasado algún tiempo i es menester mucho más para que venga a noticia del teniente de correjidor que vive en el rio de los españoles de quienes regularmente se ocultan los indios sus defectos siendo por este motivo siempre mui tarde el remedio i las más veces inútil; porque siendo dueños de la cordillera se pasan al otro lado cuando no consiguen ocultarse entre las quebradas de sus terrenos i lo propio sucede con cuales quiera otros delincuentes estraños que se refugian al asilo de los indios". 6

Por ello, las características geográficas del territorio del Huasco Alto configuraron en el periodo colonial el imaginario de confín geográfico y de refugio indígena. El primero un lugar inaccesible especialmente, los potreros de la cordillera, las serranías y las quebradas, que quedaban más allá de la vista, como plus ultra, a los que pocos podían acceder. Pero también como territorio "desordenado" escasamente sujeto a las normativas coloniales, y como lugar donde el derecho consuetudinario y el ordenamiento indígena del espacio favorecieron su autonomía.

\section{Pueblo de Indios}

Fue en la cuenca del río de los Indios, de los Naturales o del río Tránsito donde se intentó constituir el Pueblo de Indios de Huasco Alto. Este era identificado en 1760 por el Gobernador Amat, en

Tomo 188, f 281 y 282, Carta de Amat al Rey de España. Santiago de Chile: Manuscritos Sala José Toribio Medina, Biblioteca Nacional. 
su historia geográfica e hidrográfica: "Pueblo de Huasco es de Indios $\left(28^{\circ} 22^{\prime}\right.$ - $311^{\circ} 28^{\prime}$ )" (Amat y Junient, 1930: 306). Esto reconocía la existencia de un territorio en poder de los indígenas, el que se extendía a lo largo de todo un valle cordillerano. Sin embargo, las ordenanzas hispanas de mensura y reducción de este territorio a Pueblo de Indios fueron inocuas. Los españoles no lograron mensurar, ni delimitar las tierras del Huasco Alto, no sólo por su extensión, sino porque cuando lo pretendieron, tuvieron la oposición de sus habitantes. El primer intento de constituir el Pueblo de Indios ocurrió a mediados del siglo XVIII, pero no alcanzó a concretarse, pues las mensuras de tierras fueron parciales. En el año 1740 se efectuó la primera mensura en el contexto de un juicio de tierras, recurriendo el Protector General de Indios en defensa de los habitantes del Pueblo de Huasco Alto. En ese momento el Protector solicitó, se "les mensure y entere las tierras más útiles y que eligieran según la ordenanza en la forma y manera siguiente- diez cuadras al cacique de dicho pueblo -5 a cada indio tributario- 3 a cada india viuda ya más de ellas ... medirá y enterará a cada 10 indios 24 cuadras por comunidad para sus sementeras y chacras y si alguna parte no llegare al número de diez indios, de y entere rata por cantidad de las 24 cuadras, las correspondientes al número de las que hubieren ..." (Silva, 1962: 113).

La ordenanza fue ejecutada en 1750, pero su implementación fue parcial. Solo comprendió las tierras ubicadas entre los lugares denominados Tatul y La Angostura, que consideraban una parte del extenso territorio ocupado por los indígenas ${ }^{7}$. En efecto, el 17 de Marzo de 1750, el Agrimensor General Rosas, señala que su mensura ha sido parcial, puesto que en "...las diligencias practicadas en el reconocimiento de las tierras y potreros que poseen los indios de Guasco alto" no visitó los potreros de la cordillera, por "...ser muy asperas las laderas por donde va el camino de ellos, a mas de los demasiados calores que aun dentro del Valle me hizieron padezer mucho.....", agregaba que el resto de las tierras quedara disponible para ser repartidas y "...aunque estas se hallan en distancia de 80 || y 100 || ....... leguas de la Villa, pudiera hazerlas apetecibles lo apreciable de los frutos que en ella se producen"8.

Las mensuras no resultaron en la entrega de tierras, ni tampoco en la constitución formal del Pueblo de Indios de Huasco Alto. Al año 1757, el Huasco Alto seguía siendo un territorio fuera del alcance efectivo de la regulación española. Se decía que era un territorio que "vivía en desorden"9. Sin embargo, el poblamiento y el uso del espacio territorial, estaba regulado por las propias normas indígenas del derecho consuetudinario. El Obispo Alday, en carta al rey de España fechada en Santiago el 2 de diciembre de 1757, reconocía todas las tierras como indígenas: "desde el principio de sus tierras en un paraje que llaman Tatul más de doce leguas hasta la mesma cordillera viviendo en este terreno separados unas de otras las familias en distancias mui crecida; algunos de los indios tienen sus majuelos cortos de viñas i en la cordillera unos potreros sin que en todo aquel territorio viva español alguno ni mas jente que los indios naturales"..$^{10}$ En el mismo año de 1757, el presidente Amat y Junient insiste en que deben ser radicados los indígenas del Huasco Alto entre

\footnotetext{
En 1642, la Real Audiencia dictó el Auto Acordado que disponía considerar un número de cuadras de tierras para los indios ausentes por si estos querían reducirse a pueblos y a la vez mandó dar una legua cuadrada, para que dentro de esta extensión se repartieran las tierras conforme a las siguientes reglas: diez cuadras al cacique, cinco cuadras a cada indio tributario o reservado, ausente o presente; tres a las viudas y veinticuatro cada diez indios, para su comunidad. Lo sobrante de la legua asignada debía quedar para sus ganados, majada y potreros, “... con sus aguas y enconadas, montes usos y costumbres..." (Silva, 1962: 108-109). 
los parajes de Tatul y la Angostura. Propone al rey de España, la asignación de este territorio limitado de fondo de valle, con el fin de someterlos al adoctrinamiento, perseguir sus costumbres, su vida libre, y apropiarse de sus territorios de cordillera:

".. remito a vuestra señoría para que en su vista se sirva dar las providencias que convengan para la sujeción de estos indios en el paraje donde tienen la iglesia hai capacidad de tres a cuatro leguas desde Tatul, principio de sus tierras hasta el paraje que llaman la Angostura que por alli se estrechan los cerros sin dejar mas plano que la caja del rio de manera que para no transitar por este cortaron en la antiguedad un peñasco de mucha altura, abriendo camino para pasar a las tierras mas superiores que llaman Chollay..; i obligando a que se congregasen en el espresado terreno de Tatul a la angostura pudieran instruirse mejor en la doctrina i evitarse los demás desordenes por estar de esta suerte distantes unos de otros, i aun pudieran ponerse en población formal: con esto se les quitaba también ser dueños de la cordillera i sobrarían tierras como también potreros que repartiéndose a españoles sirvieran de sujetar por aquella parte los indios."11

Este plan de reducción no dio resultados, lo que impidió nuevamente la constitución formal del pueblo de indios de Huasco Alto. Sus habitantes conservaron sus tierras hasta fines de la colonia. En 1789, se decía sobre la superficie del Pueblo de Huasco Alto estaba: "...compuesta en más de 30 leguas hasta su confín, que es el pie de la cordillera..."12

La permanencia territorial continuó durante el periodo republicano. A inicios del siglo XIX el Pueblo de Indios de Huasco Alto logró esquivar las leyes de liquidación de tierras indígenas aplicadas en el Norte Chico y Chile Central. La primera de ella dictada el 10 de junio de 1826, ordenó la mensura y la constitución de la propiedad individual, disponiendo que las tierras sobrantes sean expropiadas y rematadas a nombre del Fisco. Años después, la Ley de 28 de junio de 1830 , ordenó aplicar irrestrictamente la Ley de 1826 para la liquidación final de las tierras de los Pueblos de Indios (Molina et al., 2005). Este proceso no alcanzó a las tierras del Huasco Alto, porque en ellas no se constituyó formalmente el pueblo de indios durante el periodo colonial y no existían planos y mensuras definitivas ${ }^{13}$.

Las tierras del Huasco Alto se mantuvieron ocupadas por los descendientes de los indígenas. Estos a inicios del siglo XX procedieron a realizar un juicio de inscripción de dominio, alegando sus derechos ancestrales y demandando los deslindes de las tierras del antiguo pueblo de indios, que consideraban las altas cumbres y divisorias de aguas de la cuenca del río Tránsito y sus afluentes los ríos Chollay, Conay y Cazadero. La resolución del Juzgado de Letras de Vallenar de fecha 18 de marzo de 1902 ordenó la inscripción de las tierras demandadas en los registros de propiedad (Pizarro et al., 2007). La fundamentación del dictamen judicial se

\footnotetext{
Tomo 188, f 283, 284 y 285. Carta de Amat al rey de España. Santiago de Chile: Manuscritos Sala José Toribio Medina, Biblioteca Nacional. Archivo Nacional de Santiago. Fondo Capitanía General, Volumen 501, No. 6395 (1789); op.cit. Silva (1962: 195)

Ejemplo de la liquidación de tierras indígenas a inicios de la República, es lo que ocurre en el pueblo de indios de Huasco Bajo, donde el 20 de marzo de 1830 el Cabildo de Freirina, acuerda la parcelación y el reparto de tierras. Lo mismo ocurre en el pueblo de indio de San Fernando de Copiapó, cuando el 5 de enero de 1836, el Cabildo local ordena su liquidación, lo que significó una sensible reducción de las posesiones indígenas; "...de esta manera se vino a concluir la obra de los conquistadores; lo que éstos habían respetado como único albergue del hogar indio, quedó de una vez atropellado, sin que contra tamaña temeridad se levantase más voz que la del cabildante don Adrián Mandiola" , escribe en 1874 el historiador regional de Copiapó, Sayago (1997).
} 
basó en la prescripción adquisitiva a favor de los huascoaltinos, que reconoce el derecho de propiedad en virtud del uso continuo, ininterrumpido, sin violencia, ni clandestinidad, durante un determinado intervalo de tiempo, que, en este caso, se remontaría, en virtud de los documentos coloniales, a lo menos a mediados del siglo XVII (Molina et al. 2005). Los huascoaltinos, nombre del gentilicio de sus habitantes, procedieron a inscribir las tierras en el Conservador de Bienes Raíces en el año 1903, con una superficie de 395.000 hectáreas, comprendidas dentro de los siguientes deslindes: "Al norte, con las Estancias de Jarilla y Ramadilla; por el sur la Cordillera de los Andes; por el oriente; Estancia de Copiapó; y por el poniente, cordón de cerros que divide el río del Tránsito del río del Carmen" (Fj 31 N49 Registro de Propiedad CBR de Vallenar, 1903)., lo que da origen a la propiedad comunitaria denominada Estancia Agrícola de los Huascoaltinos (ver Figuras $\mathrm{N}^{\circ} 1$ y $\mathrm{N}^{\circ} 2$ ).

Figura $\mathrm{N}^{\circ} 1$

Mapa del territorio diaguita de los Huascoaltinos delimitado por líneas de altas cumbres, que encierra la cuenca del río Tránsito y sus afluentes, y diferenciación de invernadas o fondos de valles agrícolas y veranadas o sectores altos dedicados al pastoreo
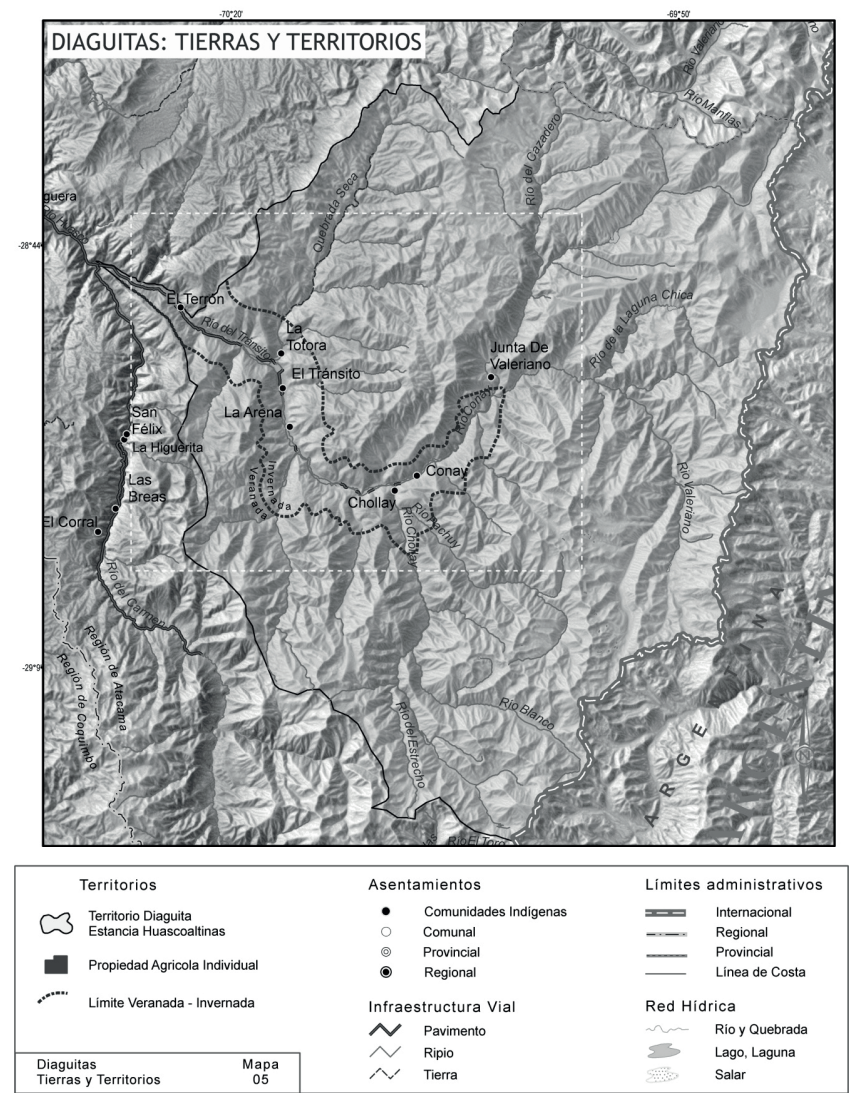

Fuente: Elaboración propia. 
Figura $\mathrm{N}^{\circ} 2$

Mapa de las localidades pobladas huascoaltinas donde se han constituido Comunidades Diaguitas y desarrollado el proceso de etnogénesis

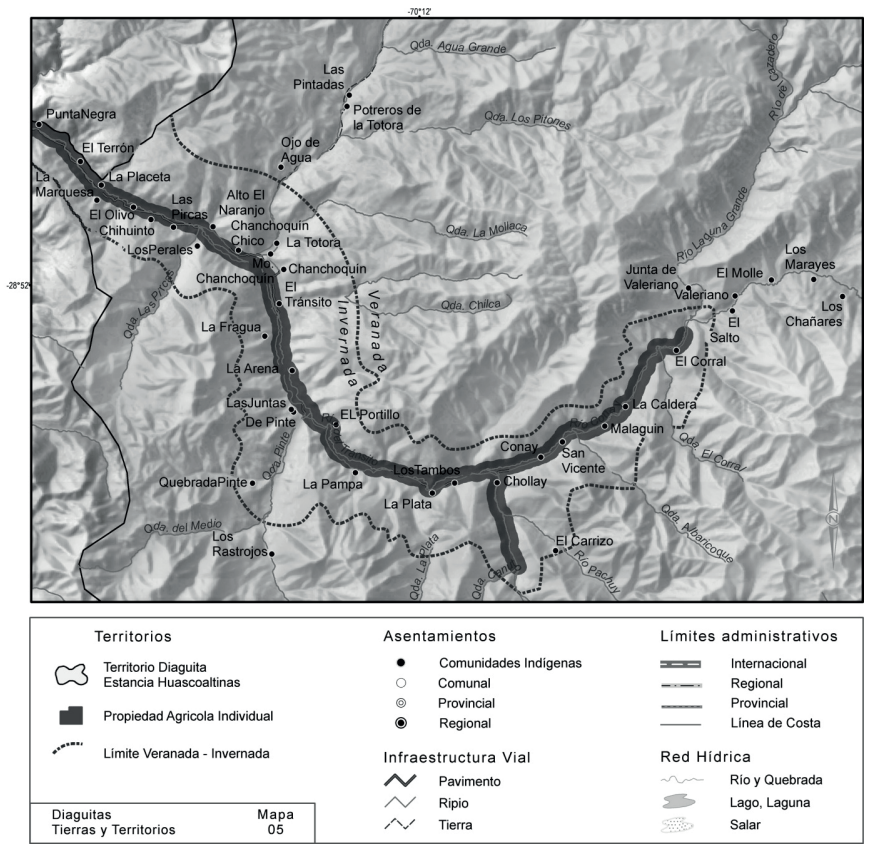

Fuente: Elaboración propia.

Durante casi un siglo las tierras del antiguo pueblo de indios colonial permanecieron a nombre de los huascoaltinos, y fueron regularizadas y vueltas a inscribir con apoyo del Ministerio de Bienes Nacionales en el año $1997^{14}$. Sin embargo, en las décadas precedentes dentro de la propiedad huascoaltina se constituyeron por particulares en las zonas altas y bajas de la cordillera y de los valles, las estancias Valeriano o Colorados, Chollay o Chañarcillos y la Estancia Pinte con una superficie aproximada de 150.000 hectáreas, lo que provocó una sobreimposición de dominio que actualmente representa uno de los principales conflictos territoriales ${ }^{15}$. A pesar de ello, los herederos del pueblo de indios continúan considerando todas las tierras propiedad ancestral, las que conservan como la base territorial que dio origen al proceso de autoreconocimiento étnico como diaguitas.

14 Inscrita a fojas 1083, Bajo el No 929, en el Registro de Propiedad del Conservador de Bienes Raíces de Vallenar, correspondiente al año 1997. El Inmueble fue adquirido por sentencia judicial dictada por el Segundo Juzgado Civil de Vallenar, en la gestión no contenciosa, rol № 9.525, de fecha 4 de agosto de 1997. En virtud de dicha sentencia se reconoció el dominio sobre el predio comunitario a todas las personas que son miembros de la Comunidad Agrícola Huasco Altinos, listado que en copia autorizada fue archivado al final del Registro de Propiedad del año 1997, bajo el № 894 al 907. Asimismo, se archivó copia autorizada del Plano № III -tres- cuatro mil cuatrocientos cincuenta y dos S.R., de los Estatutos de la Comunidad y del comparendo en el que consta el Primer directorio de la misma. Estos documentos se archivan en el Registro de Propiedad del año 1997 bajo los № 908 al 923.

15 La propiedad comunitaria de la Estancia de los Huascoaltinos ya no era de 395.000 hestáreas sino de 239.918,881 hectáreas, es decir solo un $60 \%$ de la superficie original. El resto de los territorios se encuentra ocupado por la Estancia Valeriano o Colorados con 87.332,985 hectáreas, la Estancia Chollay o Chañarcillos: con 50.712,108 hectáreas y la Estancia Pinte", de 12.089,34 hectáreas. 


\section{Autonomía económica y persistencia territorial}

La conservación del territorio geográfico por los habitantes del pueblo de indios colonial y por los huascoaltinos del periodo republicano, no sólo tuvo como aliado estar confinados en la cordiIlera, sino también, lo fue su actividad económica basada en la agricultura que aprovechó las tierras fértiles, las aguas del río Tránsito y el clima templado de la región cordillerana, que favoreció los cultivos y la explotación ganadera desde periodos coloniales. Esto benefició la producción, autoabastecimiento y la autonomía económica indígena.

Desde el periodo de contacto indígena-español, Vivar (2001) reporta para el Valle del Huasco, cultivos de "maíz e frizoles e quinoa y zapallos, ...Cojesé aji" También cultivaban el algodón, del que hacían una parte de sus prendas de vestir "aunque no se coge mucho". Además, fabricaban bebidas alcohólicas, ".... beben el vino que hacen artificial del algarroba y maíz", y recolectan el Neguey, que es fruto de los cactus. La agricultura era de riego; "Por las acequias hay hierbas de nuestra España que son cerrajas e apio y hierba mora y llantén e verbena y de otras maneras de hierbas" (Vivar, 2001: 81). El riego agrícola es probable haya sido mejorado o introducido por el inca, y hasta la actualidad existe la denominación "Camayoc", para el responsable de repartir y cobrar las aguas de los canales que riegan los terrenos agrícolas (Molina et al., 2005). A mediados del siglo XVIII ya se cultivaban viñas y se mantenía ganado en la cordillera. El Padre Alday en su visita al Pueblo de Indios de Huasco Alto, señala que: "..algunos de los indios tienen sus majuelos cortos de viñas i en la cordillera unos potreros sin que en todo aquel territorio viva español alguno ni mas jente que los indios naturales ${ }^{\prime 16}$. En 1750, los fondos de valles del Huasco Alto se encontraban cultivados y regados con canales, desde el lugar llamado Tatul hasta los Corrales: "Sobre tierras de Indios en Huasco Alto... hallaron fructíferas y abiles de producir cualesquiera semilla que en ella..., todas las quales se hallan debajo de sequia y agua con que se riegan..."17.

Durante el siglo XIX, periodo republicano, los huascoaltinos prosiguen su desarrollo agrícola, lo que mostrará su agencia en la continuidad de su actividad económica territorial. En 1821, la agricultura huascoaltina aparece vinculada a la minería regional, abasteciéndola con la producción de higos secos, que "...se cosechaban en mucha cantidad por el gran consumo que tenían en las minas, a las cuales se daba abasto con la cosecha de 2.000 fanegas que se hacía en Huasco Alto todos los años con el precio de 6 a 7 pesos la fanega..." (Morales, 1896: 190). En 1832 en el Huasco Alto "se cosechaban en el año 2.900 fanegas de higos secos, 600 arrobas de vino y 80 arrobas de aguardiente, existiendo además tres molinos" (Morales, 1896: 196). El uso y aprovechamiento de las aguas del río Tránsito, será el otro tema que ocupará a los huascoaltinos. En 1819 se nombran los primeros Jueces de Aguas o celadores debido a la escasez que provocaban las sequías y la demanda realizada aguas abajo en el valle del Huasco "...recayendo estos cargos en los subdelegados de Huasco Alto, don Diego Zavala en el Tránsito y don Agustín Quezada en el rió del Cármen..." (Morales, 1896: 101). En las décadas posteriores, especialmente en la segunda mitad del siglo XIX, el tema del reparto del agua involucra a los huascoaltinos, estableciéndose cuotas y turnos, reduciéndoles los turnos en beneficio de los demás regantes del Valle del Carmen o San Félix. En 1880 se consagran nuevos turnos de aguas para todo el valle del Huasco que los huascoaltinos impugnan, pues lo consideran injusto debido a "La inferioridad en que quedan

\footnotetext{
Tomo 188, f 280 y f 281, Carta del Amat al rey de España. Santiago de Chile: Manuscritos Sala José Toribio Medina, Biblioteca Nacional. Archivo Nacional de Santiago. Fondo Capitanía General, Volumen: 578, Año: 1750, Fojas: 40 a 61 vta.
} 
los regantes del río El Tránsito, a quienes se obliga al "desagüe" de sus canales de dos días por semana, aunque tiene mayor hectáreaje y mayor número de habitantes que los agricultores del valle del Carmen" (Aranda, 1966: 29).

Las lagunas de la cordillera, ubicadas en el Huasco Alto fueron objeto de intervención para aumentar el embalsamiento de aguas mediante un decreto de 1898, aprobado por el Congreso de Chile. Terminadas las obras, en el año 1927, quedó establecida la cantidad de 1.554 acciones de aguas y 2.538 horas túrnales para el Huasco Alto (Aranda, 1969). Estos derechos de aguas fueron reinscritos a fines del siglo XX, en virtud del Código de Aguas, para los ríos Tránsito, Valeriano, Cazadero y Chollay, desde los cuales actualmente se toman la aguas a través de 152 canales de regadío que reparten el recurso hídrico a 1.081 personas y sucesiones familiares de las localidades de Juntas del Carmen, Ramadilla, El Tabaco, Punta Negra, El Terrón, Las Placetas, Marquesa, El Olivo, Chiguinto, Las Pircas, Los Perales - Alto y Bajo, Chanchoquin Chico, Chanchoquin Grande, El Tránsito, La Fragua, La Arena Alta y Baja, Pinte, La Angostura, La Pampa, El Parral, La Plata, Los Tambos, Quebrada de Colpe, Conay, Chollay, Pachuy, Albaricoque, Malaguin, El Corral y Juntas de Valeriano.

La actividad económica y la inserción de los huascoaltinos en los procesos de desarrollo regional acentuaron durante la república su condición de campesinos, pero no pudieron hacer olvidar su historia territorial y su identidad indígena de la que derivaban. Estas actividades económicas reflejan tanto la base indígena readaptada con elementos hispánicos (actividades de criancería, control de los canales de regadío, uso de plantas medicinales, caza del huanaco, uso de piedras de moler prehispánicas, fabricación de cerámicas y de textiles), con actividades de origen europeo que se volvieron tradicionales de la región (producción de frutos secos, cultivo de uvas, producción de vino y arrope y la incorporación del ganado caprino). Sobre las bases geográficas, territoriales y productivas, en el Huasco Alto se comenzó a reactivar una memoria indígena, dando origen al proceso de etnogénesis en la primera década del siglo XXI.

\section{Etnogénesis en el Huasco Alto}

Planteamos que la etnogénesis huascoaltina construyó un imaginario histórico, una memoria y un auto reconocimiento que tuvo como base el territorio conservado. Esta etnogénesis, adquirió un doble sentido, uno interno y otro externo (Bartolomé 2006), es decir un auto reconocimiento de la población huascoaltina como diaguita a partir del año 2000 y un reconocimiento del Estado en 2006 a través de su inclusión en la Ley Indígena 19.253. Lo relevante es que la etnogénesis diaguita de los huascoaltinos se construyó, como una agencia de la identidad local (Appadurai 2001), la que dibujó una nueva identidad en virtud de su historia indígena, sus apellidos vinculados a la lengua kakan, su localización dentro de territorios considerados diaguitas en periodos prehispánicos, entre los cuales se encontraba el Pueblo de Indios de Huasco Alto. Este era un territorio ancestralmente ocupado y connotado material y simbólicamente por las prácticas económicas y culturales de su población. Lo anterior no quiere decir que la identidad diaguita en el Huasco Alto se haya mantenido sin cambios desde tiempos prehispánicos. Según Cardoso de Oliveria (1976) las identidades étnicas se construyen en largos procesos de relación con otros pueblos, constituyéndose como identidades contrastivas de carácter procesal. En este tránsito identitario algunos elementos culturales permanecen como bases culturales de la identidad tales como el territorio, la lengua, la comida, los sistemas de creencias, los vínculos familiares y las actividades 
económicas, bastando que sólo algunas de estas prácticas se mantengan para poder sustentar tanto la mantención de la identidad étnica a lo largo de los años, como también su reaparición. Como plantea Bello (2016) se debe ser cuidadoso al pensar las identidades con características esenciales, si bien no se debe dejar de considerar los elementos de continuidad que sin duda están presentes como en el caso del Huasco Alto.

Lo nuevo de la etnogénesis huascoaltina no fue su carácter indígena, sino la identificación de su población con el etnónimo diaguita. Efectivamente, el Huasco Alto durante todo el periodo colonial fue reconocido como un espacio indígena, incluso como se indicó, se trató de constituir el pueblo de indios por la administración colonial. Sin embargo, no se conoce más nombre que el genérico de "indios" dado a los habitantes del Huasco Alto por el régimen español. Durante los siglos coloniales, el etnónimo diaguita quedó reservado para nombrar a los habitantes del valle de Elqui y los valles Calchaquíes y enseguida, durante el periodo republicano, las identitidades étnicas del Norte Chico y Zona Central del país fueron homologadas a chilenos a partir de lo señalado por el decreto de Bernardo O'Higgins de 1819 y sometidos a partir de entonces a un proceso de invisibilización y de ocultamiento de su identidad.

A pesar de la desaparición por decreto de las identidades étnicas, el Huasco Alto siguió conservando su carácter indígena en la primera mitad del siglo XIX, como lo señaló el sabio polaco Ignacio Domeyko en 1840 "...entre las montañas, en una grieta continental permanece de los tiempos precolombinos el reducto indio Guasco Alto, cuyos habitantes conservan el color y las facciones de los americanos primitivos, aunque olvidaron ya el idioma y las costumbres antiguas." (Domeyko, 1977: 388). Incluso, décadas después, para el año 1880, con motivo de las disputas de aguas entre los pobladores del río Tránsito y del río del Carmen, se decía "Es conveniente anotar que el valle de El Tránsito estaba poblado por los descendientes de indígenas y el valle del Carmen por españoles y sus descendientes" (Aranda, 1966: 29). De igual convicción era el historiador regional Morales (1981 [1896]), que destacaba la descendencia indígena de sus habitantes. Sin embargo, las anotaciones sobre el carácter indígena del Huasco Alto desaparecen en el siglo XX. Solo a inicios del presente siglo, Lorca (2002) constata el carácter indígena de la población del Huasco Alto y la existencia de una realidad étnica que prefiere no concluir sobre su adscripción. Estas mismas constataciones se podían recuperar en muchos relatos referidos a lugares de memoria (Nora, 2009; Molina, 2014) que evocaban o contenían narraciones que dan particularidad a la historia territorial. Por ejemplo, en Albaricoque, cerca de Conay, relata un poblador: "Bajo la sombra de este árbol, dicen los abuelos, se reunían los indios. Aquí el Cacique Pacolicuime mandaba a su gente" (Carlos Gallo Mauras, octubre 2001)18 y otro poblador de Chigüinto, relata: “...los nombres nativos de acá son Campillay, Guanchicai, Liquitai, eso son los apellidos nativos de este valle". (Mino Campillay, febrero de 2005). En estos testimonios se vinculan los lugares con poblamiento y presencia indígena, y se evoca el pasado y presente de la población originaria del valle.

A principios de la década del 2000 , la inquietud que rondaba entre los huascoaltinos, no era solo reconocerse indígenas, sino más bien se preguntaban ¿a qué etnia pertenecían? Los primeros estudios no daban luces acerca de su posible adscripción étnica a alguno de los pueblos

\footnotetext{
Don Ramón Paco Licuime, cacique de edad de veinte y ocho años, ausente . el apellido Pacolicuimi, o después sólo Licuime, continúa presente en los documentos coloniales de 1792 y 1796, y luego aparecen en documentos del tiempo republicano, como en la inscripción de tierras de 1903 de la Estancia de los Huascoaltinos. Continúa este apellido hasta la actualidad, como un linaje que está presente en los diversos poblados del valle.
} 
indígenas reconocidos en la tradición histórica y por el Estado de Chile en la Ley Indígena de 1993. Reconocerlos como indígenas huascoaltinos no estaba en los anales ni en la voluntad política del Estado, era necesaria una etnia reconocida por el discurso oficial. Cassigoli y Rodríguez (1995) en un primer estudio exploratorio, propusieron incluir a los huascoaltinos como parte de los collas, comunidades indígenas que se encontraban en la provincia de Copiapó. Lorca (2002) en su estudio antropológico, aportó antecedentes que podrían haber ayudado a los huascoaltinos a definir un etnónimo. Anterior a esta fecha solo existe una referencia general a la existencia de los diaguitas. Esta es pronunciada en el año 1971 por la Cámara de Diputados de Chile en el contexto de la discusión de la Ley Indígena 17.729. En un documento de su 35ª sesión, se consideró la existencia en el norte del país de una población diaguita, la que, junto a atacameños y changos, se estimaba en 20.000 personas que "conservan algunas formas de vida y tradiciones". Sin embargo, esta alusión a los diaguitas quedó archivada, sin contarse con mayores antecedentes hasta 2001, cuando se formó la Comisión de Verdad Histórica y Nuevo Trato, la que entre otros documentos contó con un ensayo histórico territorial, escrito por Molina (1997), denominado "Refugio Diaguita Huascoaltino". Este documento contribuyó a que evidenciaban cierta relación histórica de los huascoaltinos con los diaguitas.

La etnogénesis diaguita o del autoreconocimiento de los huascoaltinos como diaguitas en la primera década del siglo XXI, se apoyó en dos elementos claves. El primero fue el carácter indígena del territorio conservado, es decir, provenir del pueblo de indios del Huasco Alto y mantener un poblamiento continuo y documentado a lo menos desde el siglo XVII; y la segunda, fue que la mayor parte de sus habitantes mantenían apellidos indígenas asociables a la lengua kakán, hablada por los diaguitas ancestrales (Nardi, 1986; Latcham, 1926, 1937). La posibilidad cierta de una asociación entre huascoaltinos y diaguitas, fue fundamentada en lo señalado por el etnólogo Ricardo Latcham en la década de 1930. Este, a través de un constante diálogo con investigadores argentinos, concluyó la necesidad de denominar "Diaguitas Chilenos" a los habitantes originarios de los valles de Copiapó, Huasco, Elqui, Limarí y Choapa. Esta propuesta la planteó en virtud de evidencias arqueológicas, dialectales y de los apellidos de los indígenas de Atacama y Coquimbo. Esta última consideración, los apellidos, otorgó un carácter histórico a los diaguitas, es decir, identidades que sobrevivieron al periodo prehispánico y los apellidos continuaron siendo llevados por muchas personas del Norte Chico.

Respecto de los apellidos diaguitas, escribe Latcham (1937: 894-895):

"La semejanza y a menudo la identidad de los apellidos es todavía más concluyente (para denominarlos Diaguitas chilenos). Entre aquellos que han se han sacado de los antiguos registros parroquiales de Copiapó, Huasco y La Serena, hallamos muchos que son iguales a los de igual procedencia argentina. De los que todavía se usan en las provincias en cuestión, podemos citar: Albayay, Abancay, Calchin, Campillay, Caymanqui, Chanquil, Casmaquil, Chavilca, Chapilca, Chupiza, Liquitay,Pachinga, Lainacache, Payman, Quilpitay, Quismachay, Sapiain, Talmay, Talinay, Tamango, Salmaca, Chillimaco, etc."

El etnólogo señala que la desinencia "ay" es típicamente kakana o antigua lengua diaguita. Esta desinencia la encontramos en algunos topónimos del Huasco Alto (ríos Conay y Chollay) y especialmente en los apellidos de los actuales pobladores, tales como: Campillay, Guanchicay, Tamblay o Liquitay, cuya genealogía se remonta a los primeros documentos y matriculas colonia- 
les del Pueblo de Indios de Huasco Alto. Retamal et al. (2003) en un estudio genealógico del linaje Tamblay logra documentar su descendencia a lo largo de 300 años, señalando que son una "... familia de origen presumiblemente diaguita, ...afincada en Huasco Alto hacia 1650, con filiación continuada hasta nuestros días". Así también otros linajes, como Campillay, poseen antecedentes coloniales y en la actualidad es el apellido más extendido del Huasco Alto: "En todo el valle son Campillay casi. La otra vez hicieron una encuesta y hay $75 \%$ de Campillay, en todo el valle, pasado de la Junta para arriba, hasta Valeriano, porque hasta allí llega la huella, de ahí siguen las lagunas, majadas de cabras y de ahí la línea divisoria Argentina- Chile" (Mino Campillay, febrero de 2005).

Es justamente esta combinación entre territorio productivo y patrimonial conservado, continuidad del poblamiento y vigencia de los principales linajes indígenas de origen kakan, los que van a constituir el auto reconocimiento de los huascoaltinos como diaguitas. A esto irán agregando otros aspectos identitarios, como la creencia en el Yastay y la conservación de actividades textiles, cerámica utilitaria y medicina natural (Moraga, 2002) de clara raigambre indígena. Finalmente, la adscripción étnica, canalizada y comunicada a través de diversas organizaciones funcionales, como la Asociación de Mujeres Rurales e Indígenas (ANAMURI) en 1998, los "Tertulianos" de Alto del Carmen en el año 2.000 (Aguirre et al., 2004), y los Centros Culturales Diaguitas, que en el año 2004 efectúan en la localidad de Alto del Carmen el Primer Encuentro Diaguita "Un pueblo vivo" (Molina, 2013; Molina et al., 2005) forman parte del proceso de etnogénesis. Estas organizaciones solicitaron el reconocimiento de los diaguitas al Congreso de Chile. El reconocimiento externo ocurrió en 2003 por la Comisión Verdad Histórica y Nuevo Trato, que se muestra de acuerdo en afirmar la existencia de los diaguitas en el Huasco Alto. Posteriormente, en virtud de los antecedentes aportados por las organizaciones al parlamento, el Estado decide la modificación de la Ley Indígena 19.253, que en 2006 pasa a reconocer la existencia de los diaguitas como pueblo originario del país. Esto genera un nuevo proceso organizacional que da forma a las comunidades diaguitas en las localidades del Valle del Huasco, lo que termina por evidenciar la relación del proceso de etnogénesis con el territorio, puesto que las comunidades se constituyen principalmente en el Huasco Alto, donde en casi todas las localidades se forman comunidades diaguitas.

En efecto, es posible decir que entre los años 2006 y 2014, en las comunas de Alto del Carmen, Vallenar y Freirina, se formaron comunidades y asociaciones indígenas diaguitas de acuerdo con la Ley 19.253. Según antecedentes de la Corporación Nacional de Desarrollo Indígena, CONADI, en la comuna de Alto del Carmen se habían constituido las comunidades El Tránsito, Yastay de Junta Valeriano, Tatul de Los Perales, Flor de Amancay de Alto del Carmen, Chanchoquin Chico, Sierra de Huachacan sector El Corral, Alta Cordillera sector La Plata, Chiguinto, Placeta, Chanchoquin Grande, Pacul sector La Arena, Conay, Cerro Bayo de Punta Negra, Los Tambos, Llastay sector El Retamo, Pingo Pingo sector La Pampa, Montañas Fértiles de Chollay, Corral Los Morados, Patay Co y El Cóndor sector La Arena. Además, se formó el Consejo Comunal Diaguita de Guascoalto, y la Asociación indígena diaguita de pirquineros, agricultores, crianceros y artesanos de El Corral. En la Comuna de Freirina se formó la comunidad diaguita Chipasse Ta Tatara, y en la Comuna de Vallernar las comunidades diaguita Chipasse Ashpa y las Asociaciones Indígenas Diaguitas Río Huasco, Chipasse Ta Maricunga y Alcota Kalchaquies herederos de la cultura diaguita. Para intentar agrupar a estas organizaciones se constituyó el Consejo Regional de Comunidades y Asociaciones Diaguitas de Atacama. Las características de todas estas organizaciones es que tienen asentamientos territoriales a lo largo del Valle del Huasco. 


\section{Reflexiones finales}

Es posible sostener que el proceso de etnogénesis diaguita del Norte Chico tiene su base histórica y territorial en los pueblos de indios formados en el periodo colonial, en los siglos XVII y XVIII. Esto permite manifestar que se trata de la autoafirmación de una identidad individual y colectiva, que reconoce un pasado indígena y una memoria espacial, que sustentan este proceso de reconocimiento íntimamente vinculado al territorio. En especial se puede afirmar que en el Huasco Alto se ha recreado una identidad indígena en el marco de un confín geográfico, cuyas características orográficas y ambientales permitieron constituirlo en lugar de refugio, zona de reproducción cultural y productiva, que ayudó a sus habitantes a conservar las tierras y mantener el poblamiento ancestral.

La población huascoaltina en este proceso de etnogénesis tuvo que encontrar un etnónimo, considerando su pasado indígena, que fue invisibilizado por los gobiernos republicanos, que se empeñaron en denominarlos genéricamente chilenos sin distinción étnica y catalogados como campesinos y crianceros. Pero la ocupación permanente de su territorio ancestral, la especificidad de sus actividades productivas relacionadas con la agricultura y la actividad criancera transhumante, las prácticas culturales subsistentes y la memoria local, además de sus apellidos, dieron la clave para la adscripción diaguita, que vino a hacer contemporáneo a un pueblo indígena, que las ciencias sociales y el Estado de Chile creyó extinguido.

La presencia de este refugio huascoaltino y las consecuencias derivadas del reconocimiento de la existencia de los diaguitas, abren importantes líneas de reflexión que permitirán evaluar los impactos de este proceso de autoidentificación que se está extendiendo a otros individuos y colectividades de otras localidades y regiones, donde la piedra angular está constituida por la estrecha y simbiótica relación entre territorio geográfico y etnogénesis. Quizás, esta sea una de las claves para entender la reemergencia indígena en Chile durante el Siglo XXI.

\section{Referencias bibliográficas}

AGUIRRE BELTRÁN, G. Regiones de refugio. El desarrollo de la comunidad y el proceso dominical en mestizoamérica. México: Instituto Indigenista Interamericano, 1967.

AGUIRRE, O.; RIVERA, P.; LICUIME, M.E; VARAS, N. y SEPÚLVEDA, A. Rescate de la memoria histórica del pueblo diaguita. Vallenar: Ministerio de Salud de Vallenar. Mimeografiado, 2004.

AMAT Y JUNIENT, M. Historia geographica e hidrographica con derrotero general correlativo al Plan de el Reyno de Chile que remite a nuestro Monarca el señor Don Carlos III. Revista Chilena de Historia y Geografía, 2004, Tomo XLIX, № 53, p. 297- 360.

APPADURAI, A. La modernidad desbordada. Montevideo: Editorial Trilce, 2001.

ARANDA, X. Evolución de la agricultura y el riego en el Norte Chico: Valle del Huasco. Informaciones Geográficas, 1966, №16, p. 9-41. 
BARTOLOMÉ, M.A. Los pobladores del "Desierto" genocidio, etnocidio y etnogénesis en la Argentina. Cuadernos de Antropología Social, 2003, N¹7, p. 162-189.

BELLO, A. ¿Pertenencia o identidad? Implicancias de dos categorías socioculturales para los derechos indígenas y la lucha contra el racismo. Revista Antropologías del Sur, 2016, Año 3, N 6, p. 13-27.

CASSIGOLI, R. y RODRÍGUEZ, A. Investigación Antropológica del Estudio Diagnóstico de la Población Colla de la III Región. (Preinforme Final). Santiago de Chile: Sur Profesionales Ltda. - Departamento de Antropología de la Universidad de Humanismo Cristiano, 1995.

CAMPOS, L. El patrimonio y las demandas de reconocimiento cultural. En: ALVARADO, M.; CAMPOS, L.; GALLARDO, F.; GÓMEZ, J.; KALAZICH, F.; MARTÍNEZ, F.; MEGE, P.; MIRANDA, P.; RAMAY, A.; SANFUENTES, O. y OSSA, B. Patrimonio y pueblos indígenas. Reflexiones desde una perspectiva interdisciplinaria e intercultural. Santiago de Chile: Editorial CIIR-Pehuén, 2016, p. 67-74.

CARDOSO DE OLIVEIRA, R. Identidade, etnia e estrutura social. Sao Paulo: Editorial Pionera, 1976.

COMUNIDAD INDÍGENA DIAGUITA TAUCÁN. Diaguitas del Valle de Chalinga: Patrimonio, Cultura e Identidad. Coquimbo: Fondo Editorial del Gobierno Regional de Coquimbo, 2014.

CORNELY, F. Cultura Diaguita Chilena y Cultura El Molle. Santiago de Chile: Editorial Pacífico, 1956.

DOMEYKO, I. Mis Viajes. Memorias de un exiliado. Tomo I. Santiago de Chile: Ediciones de la Universidad de Chile, 1977.

ESCOLAR, D. Identidades emergentes en la frontera argentino-chilena. Subjetividad y crisis de soberanía en la población andina de la provincia de San Juan. En: GRIMSON, A. (compilador). Fronteras, naciones e identidades. La periferia como centro. Buenos Aires: Ediciones CICCUS - La Crijía, 2000, p. 256-277.

ESCOLAR, D. Los dones étnicos de la nación. Buenos Aires: Editorial Prometeo, 2007.

IRIBARREN, J. Arqueología del Valle del Huasco. Provincia de Atacama. Revista Universitaria, 1956, Años XI y XLI, N01, p. 183-212.

ISLA, A. Los usos políticos de la identidad. Indigenismo y Estado. Buenos Aires: Editorial de las Ciencias, 2002.

CARDOSO DE OLIVEIRA, R. Identidade, etnia e estrutura social. Sao Paulo: Editorial Pionera, 1976.

LATCHAM, R. Los indios antiguos de Copiapó y Coquimbo. Revista Universitaria, 1926, Año XI, Nº 10, p. 892-905

LATCHAM, R. Arqueología de los Indios Diaguitas. Boletín del Museo de Historia Natural, 1937, Tomo XVI, p. 17-35. 
LINDÓN, A. y HIERNAUX, D. (editores). Geografías de lo imaginario. México: UAM, Anthropos, 2012.

LORCA, M. Hacia Una Antropología de las Ausencias. El Desarrollo Histórico - Étnico del Huasco Alto. Santiago de Chile: Ediciones Municipalidad de Alto del Carmen, Fundación Nacional para la Superación de la Pobreza y Fundación Volcán Calbuco - LOM editores, 2002.

LUNA, G. Trayectoria crítica del concepto de Etnogénesis. Logos: Revista de Lingüística, Filosofía y Literatura, 2014, Vol. 24. N² 2, p.167-179.

MOLINA, R. El Refugio Diaguita del Huasco Alto. Manuscrito inédito, 1997.

MOLINA, R. Diaguitas: Dialéctica de las relaciones y conflictos interculturales en el Huasco Alto. En: Relaciones Interculturales y Pueblos Indígenas en Chile. Santiago de Chile: Programa de Naciones Unidas Para el Desarrollo, 2013.

MOLINA, R. Pueblo de Indios Huasco Alto, Lugar de Memoria y fantasmas de la etnicidad. En: BISIATTI, S. y COMPAÑY, G. (compiladores). Memorias Sujetadas: Hacia una lectura crítica y situada de los procesos de memorialización. Madrid: JAS-Arquelogía, p. 35-52, 2014.

MOLINA, R.; CAMPOS, L.; YÁÑEZ, N.; CORREA, M.; SINCLAIRE, C.; CABELLO, G.; CAMPOS, P.; PIZARRO, I. y ABALLAY, M. Diagnóstico Sociocultural de la Etnia Diaguita en el III Región de Atacama; Informe Síntesis. Copiapó: Grupo de Investigación TEPU - Informe SERPLAC, Atacama, 2005.

MORAGA, J. Estudio exploratorio del saber alopático en el valle de El Tránsito en la comuna de Alto del Carmen. Santiago de Chile: Informe Borrador, Ministerio de Salud, 2002.

MORALES, J. Historia del Huasco. La Serena: Universidad de La Serena, Segunda Edición, 1981 [1896].

NARDI, R. Observaciones sobre los nombres indígenas documentados en el noroeste argentino. En: GENTILE, M. (editor). El "control vertical" en el noroeste argentino. Buenos Aires: Casimiro Quirós Ediciones, 1986, p. 170-174.

NORA, P. Pierre Nora en Les Lieux de Mémorie. Santiago de Chile: LOM Ediciones, 2009.

PÉREZ ROSALES, V. Ensayo sobre Chile. Santiago de Chile: Ediciones de la Universidad de Chile, 1986 [1859].

PIZARRO, I.; CAMPOS, P.; MONTERO, C. y CAMPUSANO, R. El Valle de los Naturales: Una mirada histórica al Pueblo Diaguita Huascoaltinos. Santiago de Chile: Mosquitos Editores, 2007.

RETAMAL, J.; CELIS, C.; DE LA CERDA, J.M.; RUIZ, C y URZÚA, J. Familias Fundadoras de Chile, 16561700. El conjunto final. Santiago de Chile: Ediciones de la Universidad Católica de Chile, 2003.

SAYAGO, J.M. Historia de Copiapó. Buenos Aires-Santiago de Chile: Editorial Francisco de Aguirre, $1997[1874]$. 
SILVA, F. Tierra y Pueblos de Indios en el Reyno de Chile. Santiago de Chile: Editorial Universidad Católica, 1962.

SOJA, E. Postmodern geographies. The reassertion of space in critical social theory. London: Verso, 1989.

VIVAR, J. Crónica de los Reinos de Chile. Madrid: Crónicas de América, Edición de Ángel Barral Gómez, 2001.

ZUSMAN, P. La Geografía Histórica, la imaginación y los imaginarios geográficos. Revista de Geografía Norte Grande, 2013, №54, p. 51-66. 